\title{
REVISTA INVASIVA (OU REVISTA ÍNTIMA) E O SISTEMA INTERAMERICANO DE DIREITOS HUMANOS ${ }^{1}$
}

\author{
INVASIVE SEARCH (OR INTIMATE SEARCH) AND THE INTER-AMERICAN HUMAN RIGHTS \\ SYSTEM
}

Henrique Napoleão Alves²

\begin{abstract}
Resumo: Entre os tipos de revistas comumente realizadas em prisões, a mais intrusiva é a revista íntima (intimate search ou body-cavity search), também chamada de revista invasiva (invasive search) e até mesmo de revista vexatória. Essa revista consiste no exame físico de orifícios corporais como a vagina e o ânus. No presente artigo, respondo a seguinte pergunta principal: as revistas invasivas são compatíveis com as normas internacionais de direitos afirmadas pelo chamado Sistema Interamericano de Direitos Humanos? Para enfrentar esse questionamento, realizei uma pesquisa documental com o intuito de levantar todos os documentos produzidos por esse sistema sobre o assunto. A pesquisa partiu de uma metodologia inédita centrada numa técnica de pesquisa avançada por sítio virtual. Os resultados mostram, em suma, que: a CIDH considerou que revistas desse tipo podem, em tese, ser compatíveis com os direitos humanos, desde que cumpram diferentes requisitos por ela identificados; nas situações concretas examinadas posteriormente pela $\mathrm{CIDH}$ as revistas praticadas foram consideradas incompatíveis; a Corte IDH decidiu um caso em que uma prática extrema de revista invasiva resultou em tortura mediante violação sexual. A principal conclusão do trabalho é a de que a prática do Sistema Interamericano como um todo mostra que dificilmente a revista invasiva poderá ser compatível com a proteção de direitos das pessoas privadas de liberdade e dos familiares ou amigos que as visitam.
\end{abstract}

Palavras-chave: Revista íntima. Revista invasiva. Revista vexatória. Direitos humanos. Sistema Interamericano.

\begin{abstract}
Among the types of searches commonly imposed in prisons, the most intrusive is the intimate search or body-cavity search (also called "invasive search" and even "vexing search"). This kind of search consists of a physical examination of body orifices such as vagina and anus. In this article, I answer the following main question: are invasive searches compatible with the international human rights protected by the InterAmerican Human Rights System? To address this question, I conducted a research in order to identify all the documents produced by the aforementioned system on this subject. The process involved an unprecedented methodology centered on a technique of advanced search in websites. The results show, in sum, that: the Inter-American Commission considered that such searches may, in theory, be compatible with human rights, provided that they meet different requirements; in the specific situations examined later by the Inter-American Commission, the searches being practiced were considered incompatible; the Inter-American Court has ruled a concrete case in which a practice of extreme invasive search amounted to torture through sexual violence. The main conclusion of the paper is that the practice of the Inter-American System as a whole shows that it is very unlikely that invasive searches may be compatible with the protection of the rights of persons deprived of liberty and of their visiting family members or friends.
\end{abstract}

Keywords: Intimate search. Invasive search. Body-cavity search. Human rights. Inter-American System.

Recebido em 12 de setembro de 2019 Avaliado em 20 de novembro de 2019 (AVALIADOR A) Avaliado em 20 de abril de 2020 (AVALIADOR B)

Aceito em 20 de abril de 2020

\footnotetext{
1 O presente artigo reflete as opiniões do seu autor em caráter individual.

2 Doutor em Direito pela Universidade Federal de Minas Gerais; Professor na Faculdade de Direito Milton Campos; Rua Sen. Milton Campos, 202, Vila da Serra, 34006-050, Nova Lima, Minas Gerais, Brasil; https://orcid.org/0000-0001-9730-7575; hnalves.dir@gmail.com
} 


\section{Introdução}

As revistas realizadas em prisões costumam se dar por contato físico sobre o corpo vestido (pat-down search ou frisk search); por exame visual com remoção parcial ou total de roupas (strip search); $;^{3}$ ou por exame físico de orifícios corporais como a vagina e o ânus. Essa última é tida como o mais intrusivo método de revista, e foi chamada de revista intima (em inglês: intimate search ou bodycavity search), assim como de revista invasiva (invasive search) (PENAL REFORM INTERNATIONAL, 2013, p. 1).

Os estudos que deram voz às pessoas submetidas a revistas invasivas e / ou a revistas visuais com remoção total ou parcial de roupas mostram que essas pessoas compreendem a experiência da revista como degradante, abusiva, constrangedora, vergonhosa, humilhante, dentre outros termos. Em virtude disso, essas práticas são também denominadas "revista vexatória" ${ }^{4}$

\footnotetext{
Durante essas últimas modalidades de revista as pessoas revistadas podem ser solicitadas a abrir a boca, a se agachar, a tossir, a levantar o pênis e os testículos e a abrir as pernas para inspeção genital (PENAL REFORM INTERNATIONAL, 2013, p. 1).

4 Conforme Dutra (2008):

"(Jacinta): Me senti como se tivesse morrendo, para mim foi horrível [...]." (p. 137).

"(Jocasta): A pequena que eu tenho tem uns 5 anos. É irmã dele. Ela diz: 'Mãe eu não vou. Vai ter que ficar tudo pelada'. Ela chorava no dia em que veio pela primeira vez realizar a revista íntima. [...] A minha filha só veio uma vez. Eu pensei que fosse dar um treco nela. (Mércia): A minha filha era revistada também. Eu achava um absurdo abaixarem a calcinha de uma criança de 5 anos. Eu sempre pedia para ela ficar grudadinha na parede quando era vez de eles me olharem." (p. 135). "(Mércia): [...] Tem lugar que é mais rigoroso. São Pedro de Alcântara é mais rigoroso. Lá além das meninas agacharem, elas têm que passar um papel na vagina e abrir a vagina para que as agentes olhem lá dentro." (p. 102).

"(Ostragilda, irmã, 54 anos): Em São Paulo a gente tinha que levantar o sutiã, abaixar a calcinha e pular." (p. 104).

"(Georgina): Tu fica nua. Eles tiram [...], você tira a tua roupa e te revistam a roupa e te revista né.

E eles fazem você abrir os órgãos sexuais?
}

Uns fazem, outros não. Nem todos os policiais são iguais." (p. 104-105).

"(Dália): A semana passada a agente penitenciária pensou que eu tivesse levando alguma coisa. Ela pediu que eu colocasse a mão lá dentro. Eu falei, não preciso disso. Eu tenho uma filha. Falei: quer que eu deite no banco e veja? Pode ver." (p. 118). "(Berenice, mãe, 56 anos): Nunca pensei que tivesse que passar por isso. Não uso droga, não uso cigarro, nada, e eles ainda tem que fazer isto? Eu trabalhei no meio de armas e nunca fui revistada. Com essa revista eu me sinto como bandida." (p. 127).

"(Acácio, irmão, 25 anos): [...] Na primeira vez que passei pela revista foi chato, fiquei meio envergonhado, não sabia como era. A minha mãe não gostou também de ser revistada. Ela reclamou com a gente. Ela não gostou de mostrar o corpo dela para outra pessoa. Ela só mostrava para o pai. A gente se sente humilhado ao fazer a revista, porque é uma coisa que a gente nunca faz. Acredito que se tivesse detector de metal ou se não tivesse que tirar a roupa toda e ficar se abaixando para os outros seria melhor. Acho que é necessário a revista, porque como eles dizem: 'Entra muita droga no presídio'. Mas é ruim porque tem que se humilhar para eles. Poderia deixar cintas, bonés, mas não tirar as calças." (p. 136).

"(Florisbela): Depois que eu saí da revista, saí chorando. Foi traumatizante. Eu lembro da minha filhinha me olhando. Ela disse bem triste. O que foi mãe, o que aconteceu com você? E eu falei. Não, nada, filha, vamos ver seu pai." (p. 138).

"O constrangimento de um homem ao ser vistoriado em seus órgãos sexuais representa uma humilhação e ofensa difícil de dimensionar, como se presumem das falas aqui elencadas. [...] (Ex-recluso, 25 anos de idade):

Sim, mas que lá dentro é diferente, que é mais rígido. Eu já apanhei muito porque no começo eu não aceitava e sentia envergonhado. [...] ([outro] Ex-recluso): Além de segurar os órgãos sexuais, deve-se agachar e abrir as nádegas e colocar a mão lá." (p. 101).

"(Clotilde, mãe, 68 anos): [...] Não tenho idade para fazer isso não. Como é obrigação eu fico acanhada." (p. 105).

"[Do]s depoimentos percebe-se que, mesmo o fato de ser a revista íntima ofensiva à dignidade humana, em alguns estabelecimentos, tal procedimento é tornado ainda mais humilhante, ao admitir que duas pessoas desconhecidas passem juntas pelo agachamento no espelho, ou que ainda tenham que abrir, em cima dele, os lábios vaginais no espelho - como é o caso de São Pedro de Alcântara." (p. 103).

"No ano de 2004 a Associação Habeas Corpus foi frequentemente requisitada pelos detentos, por meio de cartas, e de familiares de detentos, que denunciavam o caráter humilhante e abusivo da revista realizada no presídio masculino de Florianópolis, em objetos e nas pessoas visitantes do sistema penitenciário." (p. 2). 
No presente artigo, respondo a seguinte pergunta principal: as revistas invasivas são compatíveis com as normas internacionais de direitos afirmadas pelo chamado Sistema Interamericano de Direitos Humanos (SIDH) ? $^{5}$

Para enfrentar esse questionamento, realizei uma pesquisa documental com o intuito de levantar os documentos produzidos por esse sistema sobre o assunto. $O$ estudo se justifica pela importância social do tema, pela posição jurídica e política do Sistema Interamericano e por representar uma contribuição original à literatura especializada. Após expor a metodologia adotada na pesquisa documental e a revisão de literatura conduzida, serão descritos, de forma sistematizada, os resultados encontrados. Ao final, serão apresentadas as observações conclusivas sobre como a prática do Sistema Interamericano como um todo mostra que muito dificilmente a revista invasiva será coerente com a proteção de direitos das pessoas privadas de liberdade e daquelas e daqueles que as visitam.

\section{Metodologia}

Os dois órgãos principais do SIDH são a Comissão Interamericana de Direitos Humanos $(\mathrm{CIDH})$ e a Corte Interamericana de Direitos Humanos (Corte IDH). Cada qual possui o seu próprio sítio virtual onde estão hospedadas decisões, relatórios e outros documentos produzidos por esses órgãos através dos anos. Cada documento tem o seu endereço virtual específico. $\bigcirc$ usuário atento perceberá que, conquanto cada endereço seja único, a comparação entre endereços permite identificar uma parcela de URL comum. ${ }^{6}$

\footnotetext{
"Na década de 80, o cadastramento era realizado na parte interna da penitenciária, no setor social e apenas para fazer a carteirinha, os familiares tinham que passar pela revista íntima pois, por questão de segurança prisional, tal procedimento deveria ser adotado. Nota-se que ainda hoje, por questões de segurança, um familiar, apenas para conversar com uma psicóloga ou assistente social tem que se submeter ao procedimento da revista íntima. [...] [O]s familiares, se sentem humilhados por passarem pela revista íntima." (p. 61 e n. 56).

Ver, também, Medeiros (2015):

"Durante a coleta de dados realizada nas rodas de conversa com as famílias, foram relatadas situações de grande constrangimento e humilhação por parte dos familiares, como senhoras idosas passando pelo procedimento, junto com outras mulheres, revista íntima vexatória sendo realizada nas crianças filhas dos adolescentes, revista realizada sem luvas, dentre outras graves violações. Maria contou que a revista é o pior momento da visita, e que só se submete a tal violação pela necessidade de ver e cuidar de seu filho, sendo que em uma das últimas visitas se sentiu tão constrangida e fragilizada que não conseguiu ficar de pé após o procedimento, necessitando da ajuda de outras pessoas para se levantar." (p. 165166). "[T]odas essas humilhações, violações e dificuldades impactam as famílias dos adolescentes que cumprem medidas socioeducativas de privação de liberdade [...]." (p. 168).

5 O Sistema Interamericano de Direitos Humanos é formado pela Comissão Interamericana de Direitos Humanos (CIDH) e pela Corte Interamericana de Direitos Humanos (Corte IDH). Nos termos do artigo 106 da Carta da Organização dos Estados Americanos (OEA), a CIDH é o órgão quase-judicial responsável por "promover o respeito e a defesa dos direitos humanos" nos 35 países membros dessa Organização, bem como servi-la como órgão consultivo. A Corte IDH, por sua vez, é o órgão judicial do Sistema. Seu mandato está estabelecido na Convenção Americana sobre Direitos Humanos (CADH). A Corte tem competência para examinar casos submetidos pelos Estados Partes da CADH e pela CIDH em relação aos países que tenham reconhecido sua jurisdição, bem como para editar medidas provisórias e opiniões consultivas (arts. 61 a 64 da CADH). Para uma introdução sobre o sistema, ver Guzmán e Quintana Osuna (2013, p. 7-9, 25-28).

6 "O Uniform Resource Locator (URL), é um termo técnico (e anglicismo de tecnologia da informação) que foi traduzido para a língua portuguesa como "localizador uniforme de recursos". Um URL se refere ao endereço de rede no qual se encontra algum recurso informático, como por exemplo um arquivo de computador ou um dispositivo periférico
} 
Vejamos um exemplo. A URL do documento que contém a decisão da Corte IDH no Caso Ximenes Lopes é: http://www.corteidh.or.cr/docs/casos/articulos/seriec_149_por.pdf. A URL do documento que contém a decisão da Corte IDH no Caso Favela Nova Brasília é: http://www. corteidh.or.cr/docs/casos/articulos/seriec_333_por.pdf. A comparação entre uma e outra mostra que há um endereço em comum (http://www.corteidh.or.cr/docs/casos/articulos/), e que a variação ocorre apenas na parte final de cada URL.

Essa URL em comum permite o uso da ferramenta de busca avançada do Google para pesquisar palavras ou expressões dentro do acervo de documentos da $\mathrm{CIDH}$ ou da Corte IDH. A presente pesquisa se valeu dessa ferramenta segundo o Quadro 1:

Quadro 1 - Parâmetros de pesquisa - busca avançada Google e site da CIDH

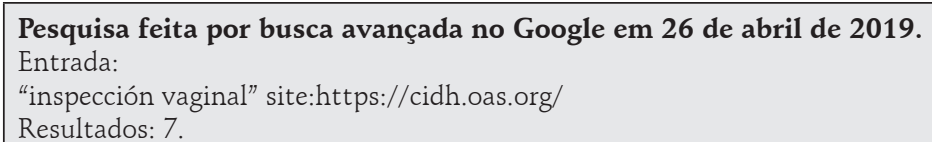

Resultados: 7 .

Complementação da pesquisa por busca avançada no Google em 02 de maio de 2019.

Entrada:

body cavity search site:https://cidh.oas.org/

Resultados: 4.

Filtros: 3 descartados por não tratarem do tema. $\bigcirc$ único relevante era a versão em inglês do relatório de mérito no caso 10.506, já abarcado pela pesquisa do dia 26 de abril de 2019 .

Entrada:

inspección anal search site:https://cidh.oas.org/

Resultados: 5.

Filtros: 4 descartados por não tratarem do tema. O único relevante era o relatório de mérito no caso 10.506, já abarcado pela pesquisa do dia 26 de abril de 2019.

\section{Parâmetros de pesquisa - busca avançada Google e site da Corte IDH}

Pesquisa feita por busca avançada no Google em 7 de maio de 2019.

Entrada:

"inspección vaginal" site:http://www.corteidh.or.cr/docs/

Resultados: 3.

Filtros: $O$ resultado principal diz respeito à decisão da Corte IDH no caso do Centro Penal Miguel Castro Castro vs. Peru.

Dos outros dois resultados, um foi descartado porque apenas mencionava a referida decisão; o outro por ser uma publicação

a respeito desse mesmo caso do Centro Penal Miguel Castro Castro vs. Peru.

Entrada:

"inspección anal" site:http://www.corteidh.or.cr/docs/

Nenhum resultado.

Fonte: o autor.

Os resultados em questão são descritos no tópico 3 a seguir. Antes de proceder a eles, devo ressaltar que outros pesquisadores poderão se beneficiar da metodologia aqui empregada, seja para investigar o mesmo tema, seja para quaisquer outros estudos sobre a prática da CIDH ou da Corte IDH, especialmente diante das limitações dos mecanismos de pesquisa atualmente disponíveis nos sítios virtuais dessas organizações.

É importante destacar para a leitora e para o leitor do presente artigo, ademais, que a mesma metodologia pode ser aplicada em várias outras instâncias. De fato, a técnica que desenvolvi

(impressora, equipamento multifuncional, unidade de rede etc.). Essa rede pode ser a Internet, uma rede corporativa (como uma intranet) etc.". URL, 2019. 
pode ser aplicada em qualquer sítio virtual que obedeça à mesma lógica de URL comum a diferentes documentos e informações. No âmbito do Direito Internacional, isso ocorre, inter alia, com o sítio virtual da Corte Internacional de Justiça (CIJ). Em minha experiência pretérita, apliquei essa mesma técnica, com êxito, em situações variadas, de pesquisa documental no acervo da CIJ até atividades preliminares de apuração de fatos e informações de conhecimento público em portais de notícias. Embora empregue a técnica há muitos anos, este é o primeiro artigo por meio do qual a torno pública, com a esperança de que possa beneficiar pesquisadores, profissionais e pessoas com curiosidade sobre o mundo jurídico em geral.

\section{Revisão da literatura}

O levantamento bibliográfico ${ }^{7}$ e a análise dos trabalhos sobre direitos humanos e revistas realizadas em prisões justifica uma das razões de relevância da pesquisa apresentada no presente artigo e sustentada em sua introdução: a de que ele representa uma contribuição original à literatura existente.

Vários dos trabalhos publicados trazem análises do tema das revistas à luz de parâmetros jurídicos de Direito interno, como é o caso do trabalho de Nicolaie Iancu sobre o sistema jurídico romeno, ${ }^{8}$ do trabalho de Shlomo Shoham sobre o sistema jurídico israelense ${ }^{9}$ e de vários trabalhos sobre o Direito estadunidense que incluem reflexões críticas sobre a jurisprudência da Suprema Corte no caso Florence v. Board of Chosen Freeholders of the County of Burlington (KEETON, 2015, p. 55-90), ${ }^{10}$

\footnotetext{
O presente artigo serve como relatório de pesquisa que incluiu uma revisão de literatura feita a partir da base de dados HeinOnline: https://heinonline.org. As buscas foram feitas entre os dias 4 e 9 de setembro de 2019 por meio dos termos "intimate search", "invasive search", "body-cavity search", "inspección vaginal" e "inspección anal" e de expressões como "human rights" e "inter-american", per se e/ou combinados entre si. Foram selecionados os resultados que tratavam do tema das revistas em relação com os direitos das pessoas afetadas.

8 Nicolaie Iancu trata de buscas como categoria geral que inclui as buscas ou revistas corporais, procurando descrevê-las a partir do que dispunha a legislação romena e de fontes da literatura especializada do mesmo país. Sobre o tema específico, salienta que pessoas privadas de liberdade podem ser coercitivamente submetidas a revistas corporais no início e no curso da execução da pena com o objetivo de prevenir situações de risco e eventos indesejados e de apreender objetos proibidos. Esse tipo de revista, segundo os parâmetros romenos citados por Iancu, deve ser realizado por pessoa do mesmo gênero e na presença de testemunhas. "Se a situação impor uma revista íntima", destacou Iancu, "esta somente pode ser realizada por médico ou enfermeiro qualificado", mantido o "respeito à dignidade pessoal." (IANCU, 2009, p. cxxx-cxxxiv).

9 No artigo, o juiz israelense Shlomo Shoham reflete sobre a legitimidade do uso de revistas invasivas como meio de evitar o ingresso e o consumo de drogas nas prisões. Seu estudo centra-se no caso Barak J in Katalan v Prisons Service, decidido pela Suprema Corte israelense em 1980. Shohan descreve como a Suprema Corte, ao decidir o caso, estabeleceu que inspeções anais coercitivas em um preso suspeito de contrabandear drogas dentro de seu corpo sem prévia regulação legislativa representam violação à integridade física e à dignidade. Para Shohan, a Corte deveria ter usado de sua "discricionariedade judicial" para buscar uma "ponderação" entre "interesses conflitantes": de um lado, o direito individual à integridade e à dignidade violados pela inspeção anal forçada; no lado oposto, o "legítimo interesse da sociedade de proteger seus cidadãos" e a "obrigação da sociedade de fornecer condições prisionais decentes aos presos e de prevenir o uso de drogas como meios de exercício de poder e subjugação do preso mais forte em prejuízo da liberdade e dignidade daqueles sob seu controle." (SHOHAM, 1992, p. 22-23).

10 Gleiberman (2013, p. 81-106), Harvard Law Review (2012, p. 206-2160), Miller (2013, p. 433-472) e Shapiro (2011, p. 131162) (artigo que examinou o caso enquanto ainda estava pendente de decisão final, salientando que o direito à proteção contra buscas e apreensões arbitrárias previsto na Quarta Emenda à Constituição dos Estados Unidos só permitiria que pessoas privadas de liberdade sejam submetidas a revistas com remoção de roupas se houver uma suspeita razoável de que a pessoa a ser revistada tem a posse de algum bem ou objeto em contrabando).
} 
e também sobre outras decisões judiciais adotadas pela Suprema Corte e por tribunais inferiores do mesmo sistema jurídico nacional. ${ }^{11}$

Os trabalhos encontrados que fazem menção expressa ao sistema interamericano, de sua parte, embora de interesse para o tema, não trazem a mesma abrangência resultante da metodologia aplicada no presente artigo, centrando-se principalmente na decisão da Comissão Interamericana no Caso 10.506. ${ }^{12}$ Como será visto na seção 3, a metodologia aplicada pelo presente artigo permitiu a identificação e a descrição de outros documentos e decisões pertinentes do sistema interamericano. À parte de demonstrar que o presente artigo contribui para a literatura existente, a revisão bibliográfica mostra que há espaço para estudos futuros que, v.g., comparem os parâmetros adotados pelos diferentes sistemas jurídicos internos e aqueles presentes nos sistemas internacionais de proteção dos direitos humanos (aí incluídos não apenas o sistema interamericano, mas também os demais sistemas regionais e o sistema universal). ${ }^{13}$ Esta senda transcende o objeto delimitado no presente artigo, mas ainda assim merece ser mencionada como encorajamento aos leitores que queiram desenvolver novos estudos sobre a questão da legitimidade das revistas ora examinadas.

\section{Revista invasiva e o SIDH: descrição dos resultados}

A pesquisa realizada mostra que a $\mathrm{CIDH}$ tratou expressamente do tema da revista invasiva em três situações principais: ao examinar o Caso 10.506 (Sra. X e sua filha Y vs. Argentina) e emitir

11 Gauthier (2011, p. 247-272) (artigo centrado no julgado da Suprema Corte dos Estados Unidos no caso Bell v. Wolfish (1979) e em como ele foi interpretado e aplicado por tribunais de instâncias inferiores do Poder Judiciário estadunidense); Rich (2009, p. 1-80) (criticando diferentes parâmetros jurisprudenciais estadunidenses sobre assédio sexual e defendendo uma nova abordagem sobre o tema, centrada na dignidade individual e assentada em subsídios teóricos e jurisprudenciais); Shapiro (2007, p. 67-108) (refletindo sobre a relação entre o direito à proteção contra buscas e apreensões arbitrárias e as revistas realizadas nas prisões a partir de pesquisa jurisprudencial sobre decisões tomadas por tribunais estadunidenses e delimitando qual abordagem sobre o tema seria compatível com a Constituição dos Estados Unidos).

12 Assim, e.g., num contexto de reflexão sobre gênero e reparações por violações internacionais de direitos humanos, Elizabeth Abi-Mershed mencionou brevemente o Caso 10.506, destacando que a própria decisão da Comissão Interamericana configura um tipo de reparação por ela estabelecer os parâmetros para qualquer tipo de revista de cavidade corporal de mulheres que sejam visitantes em prisões, assim como determinar que o Estado adote medidas legislativas para tornar seu sistema jurídico compatível com a Convenção Americana (ABI-MERSHED, 2007, p. 1446). O excelente artigo de Koury e França, por sua vez, pretendeu analisar o sentido e o alcance do direito à integridade pessoal previsto na Convenção Americana de Direitos Humanos por meio da análise da Convenção e dos termos por ela aplicados, assim como de outros marcos jurídicos de direito internacional dos direitos humanos (como a Convenção Interamericana para Prevenir e Punir a Tortura; a Convenção Europeia de Direitos Humanos e a Convenção Europeia para Prevenir a Tortura e as Penas ou Tratos Desumanos e Degradantes; e a Convenção das Nações Unidas contra a Tortura e Outras Penas ou Tratamentos Cruéis, Desumanos ou Degradantes); assim como de pesquisa sobre como a jurisprudência internacional e a literatura especializada interpretam esse direito. Ao tratar especificamente da inter-relação entre o direito à integridade pessoal e o devido processo legal, Koury e França refletem sobre o sentido e o alcance do art. 5.3 da Convenção Americana ("a pena não pode passar da pessoa do delinquente") e, ao fazêlo, mencionam brevemente as decisões de mérito adotadas pela Comissão Interamericana no Caso Alan García v. Peru e no Caso 10.056. Ainda sobre o art. 5.3 da Convenção, Koury e França corretamente apontam que a origem dessa norma reside "na proibição de castigos coletivos prevista nas Convenções de Genebra, as quais estabelecem padrões mínimos de respeito à dignidade humana", e ecoa também no art. 7.2 da Carta Africana dos Direitos Humanos e dos Povos (segundo o qual "A pena é pessoal e pode atingir apenas o delinquente") (KOURY; FRANÇA, 2007, p. 33).

${ }^{13}$ Além dos trabalhos citados acima, outra fonte interessante de pesquisa para quem quiser se aventurar por esse caminho é o levantamento jurisprudencial feito pela Seção de Jurisprudência Internacional do Supremo Tribunal Federal sobre Revista Íntima. Publicado em dezembro de 2018, o documento cita decisões judiciais sobre o tema de tribunais da Alemanha, do Canadá e dos Estados Unidos, além de decisões tomadas pela Corte Europeia de Direitos Humanos, pela Corte Interamericana de Direitos Humanos e pela Comissão Interamericana de Direitos Humanos (SUPREMO TRIBUNAL FEDERAL, 2018). 
uma decisão de mérito; ao retomar expressamente os parâmetros adotados na decisão relativa ao Caso 10.506, aplicando-os no contexto de relatórios temáticos e de relatórios sobre Estados específicos; ao reprovar a aplicação do procedimento de revista invasiva no contexto de um relatório sobre um Estado específico, sem fazer menção expressa à decisão no Caso 10.506, entendendo esse tipo de revista como humilhação contrária aos direitos humanos dos familiares dos presos.

No âmbito da jurisprudência da Corte IDH sobre a matéria, por sua vez, a grande referência é a sentença adotada por esse tribunal internacional no Caso do Centro Penal Miguel Castro Castro vs. Peru, de novembro de 2006.

\subsection{Revista invasiva e a CIDH}

\subsubsection{A decisão de mérito no Caso $\mathbf{1 0 . 5 0 6}$}

Em 29 de dezembro de 1989, a Comissão recebeu a denúncia de que as autoridades penitenciárias da Argentina realizavam rotineiramente inspeções vaginais em visitantes de uma unidade prisional; que a senhora X sofreu inspeções desse tipo em todas as visitas feitas ao marido; e que essas inspeções foram impostas também à filha da senhora X, então uma criança de treze anos de idade. ${ }^{14}$

O Estado alegou, em suma, que as inspeções: estavam autorizadas pelo artigo 92 da Lei Penitenciária Nacional (Decreto-Lei n. 412/1958, ratificado pela Lei n. 14.467), cujo teor seria compatível com as Regras Minimas das Nações Unidas para o Tratamento de Reclusos; ${ }^{15}$ eram realizadas por funcionárias mulheres e não envolviam a introdução de instrumentos na cavidade vaginal; ${ }^{16}$ eram realizadas por funcionários homens para averiguar a cavidade anal de visitantes do sexo masculino; ${ }^{17}$ tinham o objetivo de impedir a introdução de armas, explosivos, drogas e outros objetos perigosos no cárcere $;^{18}$ seriam autorizadas também em países europeus e nos Estados Unidos; ${ }^{19}$ eram feitas somente para visitantes que queriam ter contato físico com os presos, sendo permitida a visita sem inspeção através de um vidro de separação; ${ }^{20}$ representariam restrições legítimas aos direitos protegidos pela Convenção, necessárias numa sociedade democrática para salvaguardar a segurança comum. ${ }^{21}$

\footnotetext{
$\overline{14} \mathrm{CIDH}$ (1996), par. 1.

${ }^{15} \mathrm{CIDH}$ (1996), par. 33.

${ }^{16} \mathrm{CIDH}$ (1996), par. 35.

${ }^{17} \mathrm{CIDH}$ (1996), par. 36.

${ }^{18} \mathrm{CIDH}$ (1996), par. 36.

19 CIDH (1996), par. 43.

${ }^{20} \mathrm{CIDH}$ (1996), par. 37.

${ }^{21} \mathrm{CIDH}$ (1996), par. 34.
} 
A CIDH admitiu o caso. ${ }^{22}$ No mérito, a Comissão em diferentes momentos do relatório indicou que a revista invasiva poderia, em tese, ser aplicada. É o que ocorre, v.g., quando a Comissão disse que revistas (em geral) podem ser aceitáveis como medida de segurança, ${ }^{23}$ e que mesmo "[a] realização de revistas ou inspeções vaginais, em certas condições, pode ser aceitável, sempre e quando a aplicação da medida siga os princípios do devido processo e resguarde os direitos protegidos pela Convenção." ${ }^{24}$ A Comissão também destacou que a liberdade pessoal do preso é restringida "e, portanto, em certos casos pode-se justificar a inspeção corporal, inclusive a revisão física invasiva, dos detentos e presos, por métodos que igualmente respeitem sua dignidade humana." 25 Apesar dessas considerações, a conclusão adotada pela Comissão foi bastante clara e forte no sentido de condenar a prática: no caso concreto, foi dito que a revista invasiva imposta à Sra. X e sua filha representou método "absolutamente inadequado e irrazoável."26

O relatório impôs uma série de limites a essa prática que decorrem das normas afirmadas pela Convenção. Nesse sentido, a Comissão esclareceu que qualquer limitação aos direitos protegidos pela Convenção deve obrigatoriamente: ser prescrita por lei e necessária para a segurança de todos; guardar relação com as demandas justas de uma sociedade democrática; ser aplicada estritamente às circunstâncias nomeadas pelo artigo 32.2 da Convenção, ${ }^{27}$ e de maneira proporcional e razoável segundo esses objetivos. ${ }^{28}$

Quanto à previsão legal, a Comissão destacou que medidas que ameaçam direitos previstos na Convenção precisam ser reguladas por normas específicas e taxativas, de modo que a regulação não confira discricionariedade ampla aos responsáveis por aplicar a norma; é preciso garantir a todas as pessoas sujeitas às medidas em questão o nível mais alto de garantia de que não serão submetidas a tratamento abusivo ou arbitrário. No caso concreto, a $\mathrm{CIDH}$ considerou que as normas legais e infralegais aplicáveis não alcançaram esse patamar. ${ }^{29}$

Quanto ao requisito relativo à promoção da segurança de todos, a Comissão reconheceu que revistas gerais podem ser aceitáveis como medida de segurança, mas que revistas ou inspeções invasivas, por serem um tipo de inspeção excepcional e muito intrusivo, não comportam uma

\footnotetext{
$22 \mathrm{CIDH}$ (1996), par. 44.

${ }^{23} \mathrm{CIDH}$ (1996), par. 68.

${ }^{24} \mathrm{CIDH}$ (1996), par. 78.

${ }^{25} \mathrm{CIDH}$ (1996), par. 76.

${ }^{26} \mathrm{CIDH}$ (1996), par. 79.

27 "Os direitos de cada pessoa são limitados pelos direitos dos demais, pela segurança de todos e pelas justas exigências do bem comum, numa sociedade democrática."

${ }^{\text {A }} \mathrm{CIDH}$ acrescenta, ademais, que "[e]m quase todos os sistemas jurídicos internos do continente existe o requisito de que agentes policiais ou funcionários de segurança contem com uma ordem judicial para realizar certas ações consideradas especialmente intrusivas ou que apresentam possibilidade de abuso. Um exemplo claro é a prática que estabelece que o domicílio de uma pessoa goza de proteção especial e não pode ser revistado sem a devida ordem de busca." (par. 82).

${ }^{28} \mathrm{CIDH}$ (1996), par. 60.

${ }^{29} \mathrm{CIDH}(1996)$, par. 61-64.
} 
aplicação generalizada ou sistematizada. ${ }^{30} \mathrm{~A} \mathrm{CIDH}$ também expressou sua preocupação com os direitos dos visitantes, em especial com o direito à vida familiar, destacando que esses direitos não devem ser automaticamente limitados apenas porque haverá contato direto dos visitantes com os presos, e que a visita não deve ser automaticamente tida como potencial ato ilícito ou ameaça grave à segurança. ${ }^{31}$

Por fim, quanto ao requisito da aplicação proporcional e razoável, a Comissão considerou que a revista em questão precisaria cumprir as seguintes condições: ser absolutamente necessária como meio para alcançar concretamente a finalidade de segurança; inexistir alternativa menos invasiva; estar a revista, em princípio, autorizada por ordem judicial; ${ }^{32}$ ser realizada unicamente por profissionais de saúde. ${ }^{33} \mathrm{~A}$ Comissão decidiu que essas condições não foram observadas. ${ }^{34}$

A Comissão destacou, dentre outros pontos, que a revista invasiva "não era a única, nem tampouco a mais eficiente [medida] para controlar o ingresso de narcóticos e outras substâncias perigosas nas penitenciárias"; 35 "outros procedimentos menos restritivos, como a inspeção dos presos e de suas celas, constituem meios mais razoáveis e eficientes para garantir a segurança interna"36 e, de fato, seria "obviamente mais simples e mais razoável inspecionar os presos depois de uma visita de contato pessoal do que submeter todas as mulheres que visitam as penitenciárias a um procedimento tão extremo." ${ }^{37} \mathrm{O}$ Estado alegou que a revista não era um procedimento obrigatório e só era realizada com o consentimento das pessoas visitantes. ${ }^{38}$ No entanto, pontuou a Comissão, "o Estado não pode propor ou solicitar que pessoas sob sua jurisdição se submetam a condições ou procedimentos que possam constituir uma violação dos direitos protegidos pela Convenção [Americana]."39 Ademais, no caso específico de crianças revistadas, inexiste possibilidade de consentir em função da idade. ${ }^{40}$

\footnotetext{
$\overline{30} \mathrm{CIDH}$ (1996), par. 68.

${ }^{31} \mathrm{CIDH}$ (1996), par. 67-68.

32 Para a CIDH, em resumo, na eventualidade de uma revista como essa ser a única disponível, inexistindo alternativa menos invasiva, ainda assim seria necessária uma ordem judicial, de modo a permitir que um juiz examine a necessidade de levar revistas desse tipo a cabo. Exceções a essa regra deveriam estar expressamente previstas em lei. ("Incluso asumiendo que no existiera un medio menos invasivo, la Comisión opina que para realizar una inspección corporal intrusiva, que había sido suspendida debido al peligro de infección del personal de la penitenciaría, es necesario que haya una orden judicial. En principio, un juez debería evaluar la necesidad de llevar a cabo esas inspecciones como requisito ineludible para una visita personal sin infringir la dignidad e integridad personal del individuo. La Comisión considera que las excepciones a esta regla deberían estar expresamente establecidas por ley.") (par. 81). A CIDH acrescenta, ademais, que "[e]m quase todos os sistemas jurídicos internos do continente existe o requisito de que agentes policiais ou funcionários de segurança contem com uma ordem judicial para realizar certas ações consideradas especialmente intrusivas ou que apresentam possibilidade de abuso. Um exemplo claro é a prática que estabelece que o domicílio de uma pessoa goza de proteção especial e não pode ser revistado sem a devida ordem de busca." (par. 82).

33 CIDH (1996), par. 72, 81-85. Ver, em especial, CIDH (1996), par. 84: "[A] realização desse tipo de revista corporal invasiva [...] só pode estar a cargo de profissionais da saúde, com a estrita observância de segurança e higiene, dado o possível risco de dano físico e moral à pessoa."

${ }^{34} \mathrm{CIDH}$ (1996), par. 73 e seguintes.

${ }^{35} \mathrm{CIDH}$ (1996), par. 75.

${ }^{36} \mathrm{CIDH}$ (1996), par. 76.

${ }^{37} \mathrm{CIDH}$ (1996), par. 76.

${ }^{38} \mathrm{CIDH}$ (1996), par. 77

${ }^{39} \mathrm{CIDH}$ (1996), par. 77.

${ }^{40} \mathrm{CIDH}$ (1996), par. 79.
} 
Ao final, a CIDH concluiu que foram violados:

a. o direito à integridade física e psíquica (artigo 5 da Convenção) da Sra. X e de sua filha pela inobservância dos requisitos necessários para que a revista não produza angústia e humilhação. ${ }^{41}$

b. o direito da Sra. X e de sua filha à proteção da honra e da dignidade (artigo 11 da Convenção), pois a revista "pode provocar sentimentos profundos de angústia e vergonha em quase todas as pessoas submetidas a ela" e, no caso concreto, representou ingerência ou interferência arbitrária por parte de funcionários públicos, não justificada por nenhuma situação muito grave. ${ }^{42}$

c. o direito da Sra. X e sua filha à proteção da família (artigo 17 da Convenção), do qual decorre a obrigação do Estado de "facilitar o contato do recluso com sua família, não obstante as restrições às liberdades pessoais que carrega consigo o encarceramento", garantindo o direito de visita ("requisito fundamental para assegurar o respeito à integridade e à liberdade pessoal dos internos" e "o direito de proteção da família"). Segundo a CIDH, o Estado, ao regulamentar o exercício do direito dos presos e familiares à proteção da família, "não pode impor condições ou levar a cabo procedimentos que constituam uma violação de qualquer dos direitos consagrados na Convenção". Ao submeter a Sra. X e sua filha a revistas vaginais, o Estado exerceu uma "interferência indevida" no direito delas à família. ${ }^{43}$

d. o direito da criança Y à proteção da infância (artigo 19 da Convenção), pois o Estado "propôs e realizou numa menor, que não tinha capacidade jurídica para consentir, um procedimento de possíveis consequências traumáticas"; e, ademais, não outorgou a Y "uma proteção mínima contra abusos ou dano físico" (como a que decorreria da observância dos requisitos da prévia apreciação judicial e da realização do procedimento por profissional da saúde). Para a $\mathrm{CIDH}$, as medidas mencionadas pelo Estado - "que as inspeções sejam realizadas na presença de um dos pais da menor", que "seja menos rigorosa" e que "procure preservar o sentido de pudor" - não são suficientes para garantir a proteção necessária. ${ }^{44}$

\footnotetext{
${ }_{41}$ CIDH (1996), par. 87, 89.

${ }^{42} \mathrm{CIDH}$ (1996), par. 91-94.

${ }^{43} \mathrm{CIDH}$ (1996), par. 98, 100.

${ }^{44}$ CIDH (1996), par. 104.
} 


\subsubsection{Documentos posteriores com enfoque nas condições fixadas pelo Caso 10.506}

A decisão adotada pela Comissão no Caso 10.506 foi mencionada no Relatório sobre a condição da mulher nas Américas, de outubro de 1998. Nele, a Comissão optou por destacar três pontos principais: a necessidade de equilíbrio entre o interesse do Estado de manter a segurança dos estabelecimentos prisionais e os direitos das pessoas; as condições ou requisitos de necessidade, prévia autorização judicial e realização por profissionais da saúde para que a revista pudesse se justificar; e a conclusão pela ocorrência de diferentes violações da Convenção Americana no caso. ${ }^{45}$ Essa abordagem foi igualmente adotada pela Comissão no Relatório Anual da Comissão de Direitos Humanos do ano de 1997, publicado em fevereiro de $1998 .{ }^{46}$

Esses mesmos parâmetros foram reiterados, ademais, no relatório da Comissão sobre a Colômbia e no relatório sobre a República Dominicana, ambos de 1999. No relatório sobre a República Dominicana, a Comissão: notou que as autoridades penitenciárias tinham a prática de realizar inspeções vaginais nas mulheres que desejassem visitas com contato pessoal com os presos; ${ }^{47}$ reiterou as condições ou requisitos mencionados, concluindo que, "de modo geral, a prática atual de revistas na República Dominicana não satisfaz esses requisitos"; 48 registrou a manifestação do Estado no sentido de ter ordenado o uso de inspeções vaginais como medida de exceção a ser aplicada somente em relação a pessoas suspeitas de contrabando de drogas e a ser realizada por enfermeiras. ${ }^{49}$ No relatório sobre a Colômbia, a Comissão: notou que diferentes centros prisionais estavam submetendo amigos e familiares dos presos a revistas invasivas somadas frequentemente a longas esperas de sete a dez horas; ${ }^{50}$ reiterou as condições ou requisitos mencionados e concluiu que o Estado não havia comprovado, até o momento, que cumpria com esses requisitos. ${ }^{51}$

A decisão adotada pela Comissão no Caso 10.506 também foi mencionada pelo Relatório sobre Terrorismo e Direitos Humanos, de 2002. Nele, a Comissão lembra a convergência entre o direito internacional dos direitos humanos e o direito internacional humanitário quanto à proteção da dignidade humana e às obrigações de tratamento humano ${ }^{52}$ e lista diferentes normas e standards de proteção, ${ }^{53}$ dentre os quais as normas da Convenção Americana tal como interpretadas e aplicadas no referido caso $10.506 .{ }^{54}$ A Comissão destacou as condições ou requisitos supracitados e como,

\footnotetext{
${ }_{45} \mathrm{CIDH}(1998 a)$, Capítulo I.

${ }^{46}$ CIDH (1998b), Capítulo 6.2.

${ }^{47}$ CIDH (1999a), Capítulo VIII, par. 298.

${ }^{48}$ CIDH (1999a), Capítulo VIII, par. 298-299.

49 CIDH (1999a), Capítulo VIII, par. 300.

${ }^{50}$ CIDH (1999b), Chapter 14, par. 41.

${ }^{51}$ CIDH (1999a), Chapter 14, par. 42.

${ }^{52} \mathrm{CIDH}$ (2002), par. 147.

${ }^{53} \mathrm{CIDH}$ (2002), par. 148 e seguintes.

${ }^{54}$ CIDH (2002), par. 177-178.
} 
no caso concreto, o método de inspeção vaginal foi considerado "absolutamente inadequado e irrazoável". ${ }^{55}$

\subsubsection{Reprovação adicional da revista invasiva no contexto de monitoramento}

No relatório da Comissão sobre a situação dos direitos humanos no Peru, no ano 2000, a Comissão informou que recebeu denúncias sobre abusos e maus tratos aos familiares que visitam os presos, como revistas invasivas; que as revistas vaginais eram conduzidas sem que as luvas da pessoa responsável fossem trocadas; e que as mulheres, além de serem tocadas invasivamente, eram também forçadas a pular seminuas e postas em posição de cócoras. ${ }^{56}$ No campo das recomendações, a Comissão determinou ao Estado, inter alia, "[q]ue respeite os direitos humanos dos familiares dos presos, para que os visitantes não sejam humilhados por exercer [o direito de visita]."57

\subsection{Revista invasiva e a Corte IDH}

Como salientado anteriormente, no âmbito da jurisprudência da Corte IDH, a grande referência sobre a matéria é a sentença do Caso do Centro Penal Miguel Castro Castro vs. Peru. Os fatos desse caso, em resumo, remontam a uma operação executada pelo governo peruano entre os dias 6 e 9 de maio de 1992 com o objetivo declarado de transferir cerca de noventa mulheres detidas no Centro Miguel Castro Castro para presídios femininos. Durante a operação, foram empregados explosivos, armas de guerra, morteiros e bombas de gás lacrimogêneo contra os presos, causando ferimentos e a morte de dezenas de pessoas. Os sobreviventes foram espancados. Houve também falta de atendimento e cuidado médico adequado em relação aos feridos. ${ }^{58}$ Uma das mulheres presas, em particular, foi submetida a uma inspeção vaginal no hospital da Polícia, realizada por agentes do Estado encapuzados, consoante prova testemunhal. Sob o pretexto de revistá-la, esses agentes penetraram bruscamente sua vagina com as mãos. ${ }^{59}$

Sobre esse último fato, a Corte afirmou que ocorre "violação sexual" também em "atos de penetração vaginais ou anais, sem o consentimento da vítima, mediante a utilização de outras partes do corpo do agressor ou objetos, assim como [n]a penetração bucal com o membro viril." 60

\footnotetext{
${ }_{55} \mathrm{CIDH}$ (2002), par. 178.

${ }^{56}$ CIDH (2000), Capítulo IX, par. 19.

57 CIDH (2000), Capítulo IX, par. 24.5.

${ }^{58}$ Corte Interamericana de Derechos Humanos (2019); Corte Interamericana de Derechos Humanos (2006, paras. 3, 160197).

59 Corte Interamericana de Derechos Humanos (2006), paras. 197.50 (e nota de rodapé 87), p. 309-310.

${ }^{60}$ Corte Interamericana de Derechos Humanos (2006), par. 310.
} 
A Corte afirmou, ademais, que a violação sexual cometida por agentes do Estado é especialmente grave e reprovável em função da vulnerabilidade da vítima e do abuso de poder por parte dos agentes envolvidos. ${ }^{61}$

A Corte pontuou também que a violação sexual, dentre os vários tipos de experiências traumáticas, é especialmente grave pela sua capacidade de provocar consequências severas, danos físicos e psicológicos cuja superação consegue ser ainda mais difícil para as vítimas, jogadas que são numa situação de humilhação física e emocional; ${ }^{62}$ que em contextos de conflito esse tipo de violência é empregado para humilhar as pessoas vistas como adversárias; ${ }^{63}$ e que as "consequências físicas, emocionais e psicológicas devastadoras" da violência sexual são agravadas quando envolvem mulheres presas. ${ }^{64}$

A partir dessas considerações, a Corte concluiu que a revista vaginal realizada no caso configurou violência sexual que também se qualifica como tortura, gerando assim responsabilidade internacional do Estado por violações às normas contidas no artigo 5.2 da Convenção Americana e nos artigos 1, 6 e 8 da Convenção Interamericana para Prevenir e Sancionar a Tortura. ${ }^{65}$

\section{Observações conclusivas}

Embora a decisão da CIDH no Caso 10.506 tenha afirmado que revistas invasivas podem, em tese, ser compatíveis com a Convenção Americana, foram também estabelecidas condições para que isso ocorra:

a) A medida precisa ser aplicada de modo coerente com a dignidade humana, com o devido processo e com os direitos previstos na Convenção.

b) A revista não prescinde de regulação prévia em lei, por meio de normas específicas e taxativas, de modo a não conferir discricionariedade para os responsáveis por aplicar a medida.

c) $\mathrm{Na}$ mesma direção de reduzir as chances de ocorrerem arbitrariedades, a medida deve estar autorizada por ordem judicial. ${ }^{66}$

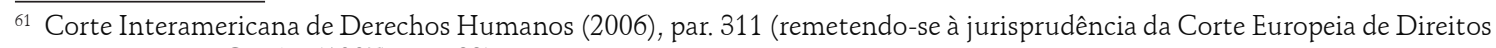
Humanos: Eur.C.H.R. (1997), par. 83).

${ }^{62}$ Corte Interamericana de Derechos Humanos (2006), par. 311 (remetendo-se a um relatório da ONU e à jurisprudência da Corte Europeia de Direitos Humanos: Organização das Nações Unidas (1995), par. 19; Eur.C.H.R. (1997), par. 83).

${ }^{63}$ Corte Interamericana de Derechos Humanos (2006), par. 313 (remetendo-se a um relatório da ONU sobre violência contra a mulher: Organização das Nações Unidas (1998), paras. 12-13).

${ }^{64}$ Corte Interamericana de Derechos Humanos (2006), par. 313 (remetendo-se aos seguintes documentos das Nações Unidas: Organização das Nações Unidas (1995), par. 16; Organização das Nações Unidas (1998), par. 14; e UN (1992), par. 35).

${ }^{65}$ Corte Interamericana de Derechos Humanos (2006), paras. 312, 432.g.

${ }^{66}$ Como descrito nas seções 3.1.1 e 3.1.2 supra, a CIDH asseverou que a medida deve estar, a princípio, autorizada por ordem judicial; e, posteriormente, afirmou a prévia autorização judicial como requisito, sem adjetivações (o que confere maior nível de proteção). 
d) A revista só poderá ser realizada por profissionais de saúde.

e) É uma medida que só se justifica se for absolutamente necessária como meio para alcançar concretamente a finalidade de segurança. Neste sentido, a simples visita e o contato direto de visitantes com presos não justificam, per se, a aplicação da medida, pois não representam potencial ato ilícito ou ameaça grave à segurança.

f) A revista deve ter caráter excepcional, ou seja, não pode ser aplicada de modo generalizado e frequente.

g) É preciso que não haja alternativa menos invasiva e menos restritiva.

Sobre esse último ponto, a própria CIDH apontou, como também visto na seção 3.1.1, um procedimento menos restritivo que pode e deve substituir revistas desse tipo: a inspeção dos presos e de suas celas (em contraposição à revista invasiva das visitantes mulheres). Ao exemplo mencionado pela CIDH podem ser acrescentados outros, como o uso de pórticos detectores semelhantes aos empregados em aeroportos.

Nos pronunciamentos subsequentes da CIDH sobre a matéria (seções 3.1.2 e 3.1.3), todas as situações de diferentes Estados supervisionadas por esse órgão foram reprovadas. Quanto à decisão da Corte IDH no caso do Centro Penal Miguel Castro Castro, os fatos estabelecidos mostram uma situação extrema de violação de direitos a partir da revista invasiva (tortura por meio de violação sexual).

A prática do Sistema Interamericano como um todo mostra, portanto, que muito dificilmente a revista invasiva poderá ser aplicada de modo coerente com a proteção de direitos das pessoas privadas de liberdade e dos familiares ou amigos que as visitam - em particular dos direitos à integridade física e psíquica, à proteção da honra e da dignidade e à proteção da família previstos nos artigos 5, 11 e 17 da Convenção Americana (e, quando aplicável, a proteção da condição do menor prevista no artigo 19 do mesmo tratado).

\section{REFERÊNCIAS}

ABI-MERSHED, Elizabeth. "Gender and Reparations". In: Reparations in the Inter-American System: A Comparative Approach. American University Law Review, [S. l.], v. 56, p. 1375-1468, 2007.

CIDH. "Capítulo I". Informe de La Comisión Interamericana de Derechos Humanos sobre la condición de la mujer en las Américas, 13 oct. 1998a.

$\mathrm{CIDH}$. "Capítulo 6.2. Jurisprudencia del sistema al encarar cuestiones relativas a género". Informe Anual de La Comisión Interamericana de Derechos Humanos 1997, feb. 1998 b.

CIDH. "Capítulo VIII. Condiciones de los Centros Penitenciarios y la situación de los prisioneros". Informe sobre la Situación de los Derechos Humanos en República Dominicana, 7 oct. 1999a. 
CIDH. "Capítulo IX. La situación penitenciaria". Segundo informe sobre la situación de los derechos humanos en el Perú, 2 jun. 2000.

CIDH. "C. Derecho a um trato humano". Informe sobre Terrorismo y Derechos Humanos, 22 oct. 2002.

CIDH. "Chapter 14. The Rights of Persons Deprived of their Liberty". Third Report on the Human Rights Situation in Colombia, 26 Feb. 1999 b.

CIDH. Informe n. 38/96. Caso 10.506. Argentina, 15 oct. 1996.

CORTE INTERAMERICANA DE DERECHOS HUMANOS. Caso del Centro Penal Miguel Castro Castro Vs. Perú. Sentencia de 25 de noviembre de 2006. (Fondo, Reparaciones y Costas).

CORTE INTERAMERICANA DE DERECHOS HUMANOS. Ficha Técnica: Penal Miguel Castro Castro Vs. Perú. Disponível em: http://www.corteidh.or.cr/cf/jurisprudencia2/ficha_tecnica.cfm?nId_Ficha $=197 \&$ lang $=$ es. Acesso em: 7 maio 2019.

DUTRA, Yuri Frederico. "Como se eu estivesse morrendo": A prisão e a revista íntima em familiares de reclusos em Florianópolis. 2008. 193 f. Dissertação (Mestrado em Direito) - Centro de Ciências Jurídicas, Universidade Federal de Santa Catarina, Florianópolis, 2008.

EUR.C.H.R. Case of Aydin v. Turkey (GC). Judgment of 25 September 1997, App. n. 57/1996/676/866.

GAUTHIER, Camille E. Is It Really That Simple: Circuits Split over Reasonable Suspicion Requirement for Visual Body-Cavity Searches of Arrestees. Tulane Law Review, [S. 1.], v. 86, p. 247-272, 2011.

GLEIBERMAN, Nina. Florence v. Board of Chosen Freeholders: Maintaining Jail Security While Stripping Detainees of Their Constitutional Rights. Maryland Law Review Endnotes, [S. l.], v. 72, p. 81-106, 2013.

GUZMÁN, Silvia Serrano; QUINTANA OSUNA, Karla. La Convención Americana sobre Derechos Humanos - Reflexiones Generales. México: CNDH, 2013.

HARVARD LAW REVIEW. Leading Cases. Harvard Law Review, [S. l.], v. 126, n. 1, p. 206-216, Nov. 2012. ("I. Constitutional Law. B. Fourth Amendment. I. Strip Searches of Prisoners").

IANCU, Nicolaie. Human Rights Protection in the Case of Performing a Search. AGORA International Journal of Juridical Sciences, [S. l.], p. cxxx-cxxxiv, 2009.

KEETON, Andre. Strip Searching in the Age of Colorblind Racism: The Disparate Impact of Florence v. Board of Chosen Freeholders of the County of Burlington. Michigan Journal of Race and Law, [S. l.], v. 21, i. 1, p. 55-90, 2015.

KOURY, Ana Beatriz Costa; FRANÇA, Clarissa Bahia Barroso. O Direito à Integridade Pessoal no marco do Sistema Interamericano de Proteção dos Direitos Humanos. Revista da Faculdade de Direito da UFMG, Belo Horizonte, n. 51, p. 19-45, jul./dez. 2007.

MEDEIROS, Fernanda Cavalcanti de. A inserção da família no processo socioeducativo de adolescentes em privação de liberdade. 2015. 188 f. Dissertação (Mestrado em Psicologia) - Centro de Ciências Humanas, Letras e Artes, Universidade Federal do Rio Grande do Norte, Natal, 2015. 
MILLER, Teresa A. Bright Lines, Black Bodies: The Florence Strip Search Case and its Dire Repercussions. Akron Law Review, [S. l.], v. 46, p. 433-472, 2013.

ORGANIZAÇÃO DAS NAÇÕES UNIDAS. Comisión de Derechos Humanos, $50^{\circ}$ Período de Sesiones. Cuestión de los derechos humanos de todas las personas sometidas a cualquier forma de detención o prisión, y en particular la tortura y otros tratos o penas crueles, inhumanos o degradantes. Informe del Relator Especial, Sr. Nigel S. Rodley, presentado con arreglo a la resolución 1992/32 de la Comisión de Derechos Humanos. Doc. E/CN.4/1995/34, 12 enero 1995.

ORGANIZAÇÃO DAS NAÇÕES UNIDAS. Comisión de Derechos Humanos, 54 Período de Sesiones. Informe presentado por la Sra. Radhika Coomaraswamy, Relatora Especial sobre la violencia contra la mujer, con inclusión de sus causas y consecuencias, de conformidad con la resolución 1997/44 de la Comisión. Doc. E/CN.4/1998/54, 26 enero 1998.

PENAL REFORM INTERNATIONAL. Body searches. London: Penal Reform International, 2013. Disponível em: https://cdn.penalreform.org/wp-content/uploads/2013/11/Factsheet-4-searches-v6_final.pdf. Acesso em: 2 maio 2019.

RICH, Camille Gear. What Dignity Demands: The Challenges of Creating Sexual Harassment Protections for Prisons and Other Nonworkplace Settings. Southern California Law Review, v. 83, i. 1, p. 1-80, 2009.

SHAPIRO, David M. Does the Fourth Amendment Permit Indiscriminate Strip Searches of Misdemeanor Arrestees? Florence v. Board of Chosen Freeholders. Charleston Law Review, [S. 1.], v. 6, p. 131-162, 2011.

SHAPIRO, Eugene L. Strip Searches: Incident to Arrest Cabining the Authority to Humiliate. North Dakota Law Review, [S. l.], v. 83, p. 67-108, 2007.

SHOHAM, Shlomo. Bodily Intrusion, Drug Search in the Human Body, Human Rights and the Balance of Interests. Medicine and Law, [S. l.], v. 11, n. 1, p. 19-31, 1992.

SUPREMO TRIBUNAL FEDERAL. Revista Íntima. Pesquisa de Jurisprudência Internacional, [S. l.], n. 16, 6 dez. 2018. Disponível em: http://www.stf.jus.br/arquivo/cms/jurisprudenciaBoletim/anexo/ Pesquisa16Revistantima.v2.pdf. Acesso em: 10 set. 2019.

UN. Commission on Human Rights, $48^{\circ}$ Session. Summary Record of the 21st Meeting, Doc. E/ CN.4/1992/SR.21, 21 Feb. 1992. 